\title{
When to use a prophylactic mesh after stoma closure: author's reply
}

\author{
C. Ramírez-Giraldo ${ }^{1,2}$ (D) A. Torres-Cuellar ${ }^{1} \cdot$ J. Navarro-Alean ${ }^{1,2}$
}

Received: 21 January 2022 / Accepted: 26 January 2022 / Published online: 5 March 2022

(c) The Author(s), under exclusive licence to Springer-Verlag France SAS, part of Springer Nature 2022

To the Editors,

We would like to thank Dr. Ajay Kumar Pal for their comments regarding our study "When to use a prophylactic mesh after stoma closure: a case-control study" $[1,2]$. In patients who presented parastomal hernia before going to stoma closure, the type of parastomal hernia they presented was not classified, their presence was only evaluated by physical examination or follow-up images. However, we consider that on future occasions, it is important piece of information, because it depends on the type of hernia, according to the classification of the European Hernia Society of parastomal hernias (recommended classification), and it could or could not be a risk factor for incisional hernia after stoma closure [3].

On the other hand, parastomal hernia was not given any particular treatment, although there is no evidence of the benefit of watchful waiting versus surgery for patients with a non-incarcerated parastomal hernia, patients with scheduled temporary stoma closure is a relative contraindication for elective surgery because the abdominal wall defect will be closed during stoma closure procedure and could also complicate stoma closure $[4,5]$.

\section{Declarations}

Conflict of interest Camilo Ramírez-Giraldo, Jorge Navarro-Alean and Andrés Torres-Cuellar declare that they have no conflict of interest.
Human and animal rights This article does not contain any studies with human participants or animals performed by any of the authors.

Informed consent Formal consent is not required.

\section{References}

1. Ramírez-Giraldo C, Torres-Cuellar A, Cala-Noriega C, FigueroaAvendaño CE, Navarro-Alean J (2020) When to use a prophylactic mesh after stoma closure: a case-control study. Hernia [Internet]. 0123456789:9-11. https://doi.org/10.1007/s10029-021-02508-3

2. Pal AK (2022) Comment to "When to use a prophylactic mesh after stoma closure: a case-control study.” Hernia. https://doi.org/ 10.1007/s10029-022-02566-1

3. Śmietański M, Szczepkowski M, Alexandre JA, Berger D, Bury $\mathrm{K}$, Conze J et al (2014) European Hernia Society classification of parastomal hernias. Hernia 18(1):1-6

4. Antoniou SA, Agresta F, Garcia Alamino JM, Berger D, Berrevoet F, Brandsma HT et al (2018) European Hernia Society guidelines on prevention and treatment of parastomal hernias. Hernia 22(1):183-198

5. Styliński R, Alzubedi A, Sł R (2018) Parastomal hernia - Current knowledge and treatment. Wideochirurgia I Inne Tech Maloinwazyjne 13(1):1-8

Publisher's Note Springer Nature remains neutral with regard to jurisdictional claims in published maps and institutional affiliations.
C. Ramírez-Giraldo

ramirezgiraldocamilo@gmail.com

1 Universidad del Rosario - Méderi, Calle 24 \#29-45, Bogotá, Colombia

2 Hospital Universitario Mayor - Méderi, Bogotá, Colombia 